\title{
MRP8 promotes Th17 differentiation via upregulation of IL-6 production by fibroblast-like synoviocytes in rheumatoid arthritis
}

\begin{abstract}
Dong-Gun Lee ${ }^{1}$, Jung-Won Woo ${ }^{1}$, Seung-Ki Kwok ${ }^{2}$, Mi-La Cho ${ }^{1}$ and Sung-Hwan Park ${ }^{2}$
Myeloid-related protein (MRP)8/MRP14 is an endogenous Toll-like receptor 4 (TLR4) ligand and is abundant in synovial fluid (SF) of rheumatoid arthritis (RA) patients. Belonging to damage-associated molecular patterns, it amplifies proinflammatory mediators and facilitates a wide range of inflammatory and autoimmune diseases. Interleukin (IL)-17-producing T-helper (Th) 17 cells have a crucial role in RA pathogenesis, and IL- 6 is the key factor promoting Th17 differentiation. We investigated whether the level of MRP8/MRP14 is positively associated with IL-6 and IL-17 levels in RA SF and found that MRP8/MRP14 level had a significant correlation with IL-6 and IL-17 levels in RA SF. We also observed that MRP8-induced IL-17 production by peripheral blood mononuclear cells but MRP14 did not. Upon stimulation with MRP8, IL-6 production was enhanced by RA fibroblast-like synoviocytes (FLS) and was further elevated by coculturing RA FLS with activated CD4 ${ }^{+} \mathrm{T}$ cells. Moreover, we demonstrated that MRP8-activated IL- 6 production by RA FLS promoted differentiation of Th17 cells using the coculture system consisting of CD4 ${ }^{+}$T cells and RA FLS. In addition, IL- 6 blockade attenuated Th17 polarization of CD4 ${ }^{+} \mathrm{T}$ cells in the cocultures. Inhibitor studies revealed that MRP8 increased IL-6 production in RA FLS via TLR4/phosphoinositide 3-kinase/ nuclear factor-KB and mitogen-activated protein kinase signaling pathways. Our results show that MRP8 has a crucial role in stimulating IL-6 expression by RA FLS, and subsequently promotes Th17 differentiation in RA, suggesting that neutralizing MRP8 level in RA synovium may be an effective therapeutic strategy in RA treatment.
\end{abstract}

Experimental \& Molecular Medicine (2013) 45, e20; doi:10.1038/emm.2013.39; published online 26 April 2013

Keywords: fibroblast-like synoviocytes; IL-6; MRP8; rheumatoid arthritis; Th17 differentiation

\section{INTRODUCTION}

Rheumatoid arthritis (RA) is a chronic autoimmune inflammatory disease characterized by synovial inflammation, and progressive cartilage and bone destruction. ${ }^{1}$ Although the precise etiology of RA remains unclear, proinflammatory cytokines and autoreactive $\mathrm{T}$ cells are crucial in its pathogenesis. Conventionally, RA is considered to be a T-helper (Th)1 cell-mediated disease, but Th17 cells are increasingly being accepted as the central factor in RA pathogenesis. ${ }^{2}$ Th17 cells produce interleukin (IL)-17A, which propagates inflammation and facilitates bone resorption by increasing the expression of RANKL on osteoblasts. ${ }^{3}$ Elevated levels of IL-17 have been observed in RA synovium and synovial fluid (SF) of patients with early RA. ${ }^{4,5} \mathrm{~A}$ critical role of $\mathrm{IL}-17$ in the development of autoimmune diseases has been demonstrated in the SKG mouse model, where self-reactive IL-17-secreting
$\mathrm{T}$ cells were shown to mediate an autoimmune arthritis close to RA. ${ }^{6}$ Inflammatory cytokines, such as IL-1 $\beta$, IL-6, IL-23 and transforming growth factor- $\beta$, provide a milieu in the local microenvironment of RA, which supports Th17 differentiation and suppresses differentiation of regulatory $\mathrm{T}$ cells, thus shifting T-cell homeostasis toward inflammation. ${ }^{7,8}$

IL-6 is an indispensable cytokine, which induces Th17 differentiation in both humans and mice in combination with IL-1 $\beta$ and transforming growth factor- $\beta$, respectively. ${ }^{9,10}$ It is abundantly present in RA SF and is known to be involved in autoimmunity by altering the balance between Th17 and regulatory T cells. ${ }^{11}$

Fibroblast-like synoviocytes (FLS) are the preponderant cells in RA synovium and produce large amounts of IL- 6 when stimulated by inflammatory cytokines, such as IL- $1 \beta$, tumor necrosis factor- $\alpha(\mathrm{TNF} \alpha)$ and IL-17.9,12 Thus, by expressing

\footnotetext{
${ }^{1}$ Rheumatism Research Center, Catholic Research Institute of Medical Science, The Catholic University of Korea, Seoul, Korea and ${ }^{2}$ Division of Rheumatology, Department of Internal Medicine, School of Medicine, The Catholic University of Korea, Seoul, Korea

Correspondence: Professor S-H Park, Division of Rheumatology, Department of Internal Medicine, School of Medicine, The Catholic University of Korea, 505 Banpo-dong, Seocho-gu, Seoul 137-701, Korea.

E-mail: rapark@catholic.ac.kr
}

Received 26 October 2012; revised 26 February 2013; accepted 5 March 2013 
high levels of disease-relevant cytokines, chemokines, adhesion molecules and matrix metalloproteinases, FLS directly contribute to local cartilage destruction and the chronicity of synovial inflammation in RA. ${ }^{13}$

Myeloid-related protein (MRP)8 and MRP14, abundantly expressed in myeloid cells, belong to damage-associated molecular patterns and have a key role in the initiation and amplification of inflammatory responses during various autoimmune disorders. ${ }^{14,15}$ MRP8 and MRP14 are also known as S100A8 and S100A9 of the family of S100 proteins, which are low-molecular weight calcium-binding proteins produced mainly by monocytes, macrophages and neutrophils, and are secreted upon activation. ${ }^{16}$ MRP8 and MRP14 are generally coexpressed and form a heterodimer complex (MRP8/MRP14). ${ }^{17}$ Once secreted, MRP8/MRP14 can bind to Toll-like receptor 4 (TLR4), which is known as the dominant receptor for MRP8/14 signaling, and exhibit proinflammatory functions leading to upregulation of a wide range of proinflammatory cytokines and activation of endothelial cells and macrophages. ${ }^{14,18}$ In RA, the MRP8/ MRP14 heterodimer accumulates in large amounts in SF and its levels strongly correlate with disease activity and structural damage. ${ }^{19,20}$ Recently, MRP8 was demonstrated to regulate joint inflammation and cartilage destruction, and to stimulate osteoclast formation and activity in experimental arthritis. ${ }^{21,22}$ MRP8 and MRP14 have also been shown to have a catabolic effect on human chondrocyte in a TLR4-dependent manner. ${ }^{23}$

In this study, we investigated whether the level of MRP8 was positively associated with the levels of IL-6 and IL-17 in RA SF compared with osteoarthritis (OA) SF. We also analyzed the effect of MRP8 on proinflammatory cytokine production by RA FLS and on the generation of Th17 lineage cells using the coculture system consisting of CD4 ${ }^{+} \mathrm{T}$ cells and RA FLS. We found that MRP8 stimulated IL-6 production by RA FLS via TLR4/phosphoinositide 3-kinase (PI3K)/nuclear factor- $\mathrm{\kappa B}$ $(\mathrm{NF}-\mathrm{\kappa B})$ and mitogen-activated protein (MAP) kinase signaling pathways. Increased IL-6 subsequently promoted Th17 differentiation, and IL- 6 blockade reduced Th17 polarization of $\mathrm{CD} 4^{+} \mathrm{T}$ cells in the cocultures.

\section{MATERIALS AND METHODS}

\section{Patients}

SF was obtained from RA patients $(n=30)$ with a mean \pm s.d. age of $55.6 \pm 11.8$ years (range 28-67 years) and OA patients $(n=20)$ with a mean \pm s.d. age of $64.4 \pm 10.8$ years (range $43-70$ years), fulfilling the 1987 revised criteria of the American College of Rheumatology. ${ }^{24}$ Synovial tissue (ST) specimens were isolated from RA patients $(n=3)$ and OA patients $(n=3)$ who were undergoing total knee replacement surgery. Normal healthy volunteers were included as controls. Informed consent was obtained from all patients and healthy volunteers before the study, and this study was approved by the Ethical Committees at Seoul St Mary's Hospital.

\section{Immunohistochemistry of RA ST}

Immunohistochemical staining for MRP8, MRP14, IL-6 and IL-17 was performed on sections of ST. Briefly, ST samples from RA and OA patients were fixed with $4 \%$ paraformaldehyde solution overnight at
$4{ }^{\circ} \mathrm{C}$, dehydrated with a graded series of alcohol, washed, embedded in paraffin and cut into $7-\mu \mathrm{m}$-thick sections. The sections were dewaxed using xylene and dehydrated in a gradient of alcohols. Endogenous peroxidase activity was quenched with $3 \%$ hydrogen peroxide in methanol. Immunohistochemistry was performed using the Vectastain ABC kit (Vector Laboratories, Burlingame, CA, USA). Tissues were incubated with primary antibody to MRP8, MRP14 and IL-6 (Abcam, Cambridge Science Park, Cambridge, UK ), and IL-17 (Santa Cruz Biotechnology, Santa Cruz, CA, USA) overnight at $4{ }^{\circ} \mathrm{C}$. The tissues were then incubated with a biotinylated secondary antibody and a streptavidin-peroxidase complex for $1 \mathrm{~h}$, followed by incubation with 3,3'-diaminobenzidine (Dako Cytomation Japan, Tokyo, Japan) for $5 \mathrm{~min}$. The sections were counterstained with Mayer's hematoxylin (Muto Pure Chemical, Tokyo, Japan). The samples were photographed using an Olympus photomicroscope.

\section{Enzyme-linked immunosorbent assay}

For enzyme-linked immunosorbent assay (ELISA) assessment of IL-6, IL-17, TNF $\alpha$ and IL-1 $\beta$ expression, a 96-well plate (Nunc) was coated overnight with $4 \mu \mathrm{g} \mathrm{ml}^{-1}$ monoclonal antibodies against IL-6, IL-17, TNF $\alpha$ and IL- $1 \beta$ (R\&D Systems, Minneapolis, MN, USA) at $4{ }^{\circ} \mathrm{C}$. After blocking with phosphate-buffered saline/1\% bovine serum albumin $/ 0.05 \%$ Tween 20 for $2 \mathrm{~h}$ at room temperature $\left(22-25^{\circ} \mathrm{C}\right)$, the test samples and standard recombinant IL-6, IL-17, TNF $\alpha$ and IL- $1 \beta$ were added to the 96 -well plate and incubated at room temperature for $2 \mathrm{~h}$. The plates were washed four times with phosphate-buffered saline/Tween 20 and then incubated with $500 \mathrm{ng} \mathrm{ml}^{-1}$ biotinylated mouse monoclonal antibodies against IL-6, IL-17, TNF $\alpha$ and IL- $1 \beta$ (R\&D Systems) for $2 \mathrm{~h}$ at room temperature. After washing, streptavidin-alkaline phosphatase-horseradish peroxidase conjugate (Sigma, St Louis, MO, USA) was added and the plate was incubated for $2 \mathrm{~h}$, after which the plate was washed again and incubated with $1 \mathrm{mg} \mathrm{ml}^{-1} \mathrm{p}$-nitrophenyl phosphate dissolved in diethanolamine (Sigma) to develop the color reaction. The reaction was quenched by the addition of $1 \mathrm{~m} \mathrm{NaOH}$ and the optical density of each well was read at $405 \mathrm{~nm}$. The lower limit of detection of IL-6, IL-17, TNF $\alpha$ and IL- $1 \beta$ was $10 \mathrm{pg} \mathrm{ml}^{-1}$. Recombinant human IL-6, IL-17, TNF $\alpha$ and IL-1 $\beta$ (R\&D Systems), diluted in the culture medium, were used as the calibration standard, in concentrations ranging from $10 \mathrm{pg} / \mathrm{ml}^{-1}$ to $2000 \mathrm{pg} \mathrm{ml}^{-1}$. A standard curve was drawn by plotting the optical density as a function of the log of the concentration of recombinant cytokines and was used to calculate IL-6, IL-17, TNF $\alpha$ and IL-1 $\beta$ in the test samples. MRP8/MRP14 was measured with an ELISA kit (HyCult Biotechnology, Uden, The Netherlands), according to the manufacturer's instructions.

\section{Isolation of human CD4 ${ }^{+} \mathrm{T}$ cell and FLS}

Human peripheral blood mononuclear cells (PBMCs) were obtained from normal healthy volunteers. Cells were separated from buffy coats by Ficoll-Hypaque (Amersham Biosciences, Uppsala, Sweden) density gradient centrifugation. $\mathrm{CD} 4{ }^{+} \mathrm{T}$ cells were isolated using a $\mathrm{CD} 4{ }^{+}$ T-cell isolation kit (Miltenyi Biotec, Bergisch Gladbach, Germany), according to the manufacturer's instructions. The purity of cells was assessed by flow cytometric analysis of stained cells on a FACS Vantage sorter (BD Biosciences, San Jose, CA, USA). Most of the isolated cells $(>97 \%)$ exhibited the $\mathrm{CD} 4{ }^{+} \mathrm{T}$ cell marker. FLS were isolated by enzymatic digestion of STs obtained from RA and OA patients undergoing total joint replacement surgery, as previously described. ${ }^{25}$ For MRP8 stimulation, CD4 ${ }^{+} \mathrm{T}$ cells and synovial fibroblasts were seeded in 24 -well plates at $5 \times 10^{5}$ cells per well in 
$500 \mu \mathrm{l} 10 \%$ RPMI 1640 and $1 \times 10^{4}$ cells per well in $1 \mathrm{ml}$ serum-free Dulbecco's modified Eagle's medium/insulin-transferrin-selenium A (Life Technologies, Gaithersburg, MD, USA), respectively, and were treated with various concentrations of MRP8 $\left(0,0.2,1\right.$ and $\left.5 \mu \mathrm{g} \mathrm{ml}^{-1}\right)$ for $72 \mathrm{~h}$. MRP8 and MRP14 were purchased from ProSpec-Tany TechnoGene Ltd (Rehovot, Israel). The culture supernatants were collected and stored at $-20{ }^{\circ} \mathrm{C}$ until assayed.

\section{Reverse-transcription PCR}

PBMCs were seeded in 24-well plates at $5 \times 10^{5}$ cells per well in $500 \mu \mathrm{l}$ $10 \%$ RPMI 1640 and were stimulated with various concentrations of MRP8 and MRP14 $\left(0,0.2,1\right.$ and $5 \mu \mathrm{g} \mathrm{ml}^{-1}$, ProSpec-Tany TechnoGene) for $72 \mathrm{~h}$. mRNA was extracted using the Tri Reagent (Molecular Research Center, Cincinnati, OH, USA), according to the manufacturer's instructions. Reverse transcription of $2 \mu \mathrm{g}$ aliquots of total mRNA was carried out at $42^{\circ} \mathrm{C}$ using the Superscript reversetranscription system (TaKaRa, Shiga, Japan). PCR amplification of cDNA aliquots was performed by adding $2.5 \mu \mathrm{m}$ dNTPs, $2.5 \mathrm{U}$ Taq DNA polymerase (TaKaRa) and $0.25 \mu \mathrm{m}$ of sense and antisense primers. The following sense and antisense primers for each molecule were used $\left(5^{\prime} \rightarrow 3^{\prime}\right)$ : IL-17, $5^{\prime}$-ATG ACT CCT GGG AAG ACC TCA TTG-3' (sense) and 5'-TTA GGC CAC ATG GTG GAC AAT CGG-3' (antisense); and $\beta$-actin, $5^{\prime}$-GGA CTT CGA GCA AGA GAT GG-3' (sense) and 5'-TGT GTT GGC GTA CAG GTC TTT G-3' (antisense). Reactions were processed in a DNA thermal cycler (PerkinElmer Cetus, Wellesley, MA, USA) through 35 cycles at $94{ }^{\circ} \mathrm{C}$ for $30 \mathrm{~s}$, at $60{ }^{\circ} \mathrm{C}$ for $30 \mathrm{~s}$ and at $72^{\circ} \mathrm{C}$ for $30 \mathrm{~s}$ for IL-17, and 25 cycles at $94^{\circ} \mathrm{C}$ for $30 \mathrm{~s}$, at $60^{\circ} \mathrm{C}$ for $30 \mathrm{~s}$ and at $72{ }^{\circ} \mathrm{C}$ for $30 \mathrm{~s}$ for $\beta$-actin.

\section{Coculture assays}

RA FLS were seeded in 24-well plates at a concentration of $1 \times 10^{4}$ cells per well in $1 \mathrm{ml}$ serum-free Dulbecco's modified Eagle's medium/ insulin-transferrin-selenium A and were cultured for 1 day. RA FLS were further incubated in the presence or absence of $5 \mu \mathrm{g} \mathrm{ml}{ }^{-1} \mathrm{MRP} 8$ for 1.5 day, and then the culture supernatant was discarded. Cocultures were initiated by adding CD4 ${ }^{+} \mathrm{T}$ cells $\left(1 \times 10^{5}\right.$ cells per well) on the top of the RA FLS layer, and were incubated for $72 \mathrm{~h}$. When mentioned, $\mathrm{CD} 4^{+} \mathrm{T}$ cells were activated in the presence of antiCD3 and CD28 $\left(0.5 \mu \mathrm{g} \mathrm{ml}^{-1}\right)$ monoclonal antibody (R\&D systems) for $2 \mathrm{~h}$. For IL-6 blockade, $2 \mu \mathrm{g} \mathrm{ml}^{-1}$ anti-IL- 6 monoclonal antibody (R\&D systems) was added into the coculture. The culture supernatants were collected and stored at $-20^{\circ} \mathrm{C}$ until assayed.

Effects of inhibitors on MRP8-avtivated signaling pathways RA FLS were seeded in 96-well plates at a concentration of $3 \times 10^{3}$ cells per well in $200 \mu \mathrm{l}$ serum-free Dulbecco's modified Eagle's medium/insulin-transferrin-selenium A for 1 day and then preincubated for $1 \mathrm{~h}$ in the presence or absence of various inhibitors $\left(5 \mu \mathrm{g} \mathrm{ml}^{-1}\right.$ anti-TLR4 antibody (HTA125), $20 \mu \mathrm{m} \mathrm{LY294002,} 1 \mu \mathrm{M}$ SP100625, 10 nм SB203580, $20 \mu$ м PD98059 (Calbiochem, Schwalbach, Germany) and $10 \mu \mathrm{m}$ parthenolide (Sigma)). After the addition of $5 \mu \mathrm{g} \mathrm{ml}^{-1}$ MRP8, RA FLS cultures were further incubated for $72 \mathrm{~h}$. The culture supernatants were collected and stored at $-20^{\circ} \mathrm{C}$ until assayed.

\section{Statistical analysis}

Statistical analyses were performed with the GraphPad Prism (Version 5 for Windows; GraphPad Software). P-values were calculated using a two-tailed (paired $t$-test) and two-way analysis of variance (grouped) analysis. $P<0.05$ was considered significant.

\section{RESULTS}

Elevated expression of MRP8, MRP14, IL-6 and IL-17 in RA ST and significant correlations among the levels of MRP8/ MRP14, IL-6, and IL-17 in RA SF

We performed immunohistochemical analyses to examine the level of expression of Mrp8, MRP14, IL-6 and IL-17 in STs from RA and OA patients. Mrp8, MRP14, IL-6 and IL-17 were expressed in higher degrees in RA ST than in OA ST as reported in the previous study (Figure 1a). ${ }^{26}$ We further assessed the amount of Mrp8/MRP14, IL-6 and IL-17 in RA SF and OA SF using ELISA. The amount of Mrp8/MRP14, IL-6 and IL-17 was significantly higher in RA SF than in OA $\mathrm{SF}$ (Figure 1b). Subsequent statistical analyses revealed that the level of IL-6, which is known to induce Th17 differentiation, correlated significantly with the level of IL-17 in RA SF. Furthermore, the expression of MRP8/MRP14 was also positively associated with the expression of IL- 6 and IL-17 in RA SF (Figure 1c).

\section{Induction of proinflammatory cytokines by MRP8 and MRP14 in PBMCs and CD4 ${ }^{+} \mathrm{T}$ cells}

To investigate the effect of MRP8 and MRP14 on the production of proinflammatory cytokines, such as TNF- $\alpha$, IL-1 $\beta$, IL- 6 and IL-17, human PBMCs were isolated from blood of healthy donors and cultured in vitro for 3 days in the presence of MRP8 or MRP14 $\left(0,0.2,1\right.$ and $\left.5 \mu \mathrm{g} \mathrm{ml}^{-1}\right)$. The levels of TNF- $\alpha$, IL-1 $\beta$, IL- 6 and IL-17 in culture supernatant were measured by ELISA. The expression of IL-17 was enhanced by MRP8 in a dose-dependent manner. In contrast to MRP8, MRP14 did not induce IL-17 in PBMCs, implicating that the functionally active component of MRP8/MRP14 complex on the induction of IL-17 in PBMCs is MRP8 but not MRP14 (Figure 2a). mRNA expression of IL-17 from PBMCs was determined by reverse-transcription PCR. In consistence with the ELISA result, only MRP8 but not MRP14 induced mRNA expression of IL-17 dose dependently (Figure $2 \mathrm{~b}$ ). The production of TNF- $\alpha$, IL- $1 \beta$ and IL- 6 was also induced by MRP8 dose dependently in PBMCs (Figure 2c). We additionally assessed whether MRP8 could directly induce expression of IL-17 in CD4 ${ }^{+} \mathrm{T}$ cells. CD4 ${ }^{+}$ $\mathrm{T}$ cells were further purified from human PBMCs and level of IL-17 was measured in the presence or absence of MRP8 using ELISA. As shown in Figure 2d, although $\mathrm{CD}^{+} \mathrm{T}$ cells produced IL-17 in the presence of anti-CD3/28 antibodies, IL-17 expression was not significantly further increased after stimulation with various concentrations of MRP8 even when $\mathrm{CD} 4{ }^{+} \mathrm{T}$ cells were activated with anti-CD3 $+\mathrm{CD} 28$ antibodies, suggesting that the induction of IL-17 in PBMCs might be the result of an indirect effect of MRP8 on the production of IL-17 by $\mathrm{CD} 4^{+} \mathrm{T}$ cells.

MRP8-induced upregulation of IL-6 production in RA FLS MRP8 and MRP14 are abundantly present in RA synovium (Figure 1a) and has an important role as damage-associated molecular patterns to activate antigen-presenting cells, such as macrophages of the innate immune system. FLS are the 
a
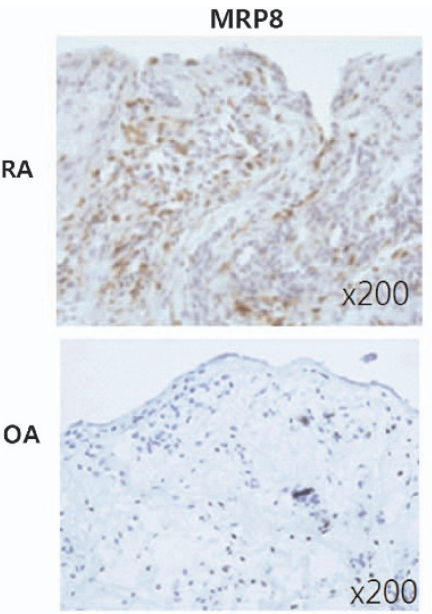

MRP14

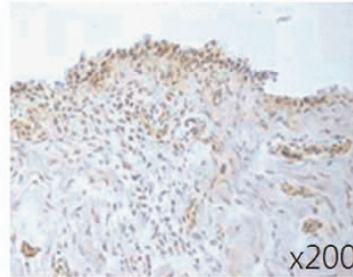

IL-6

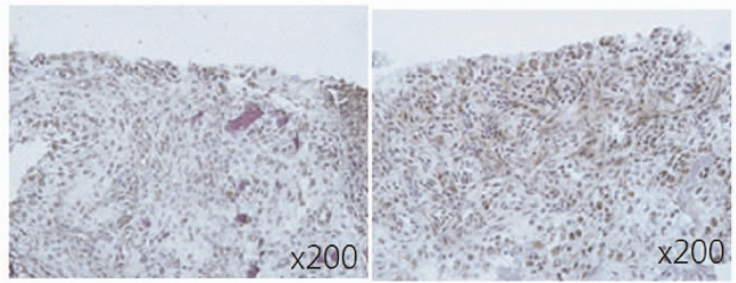

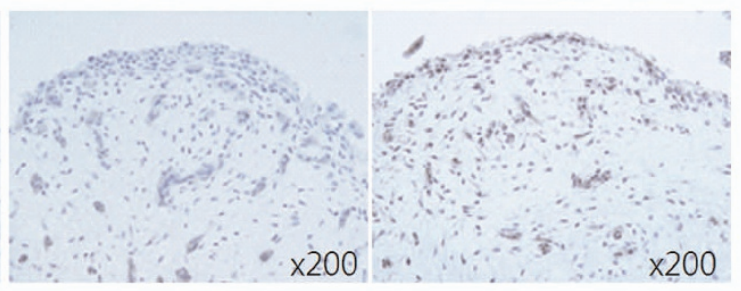
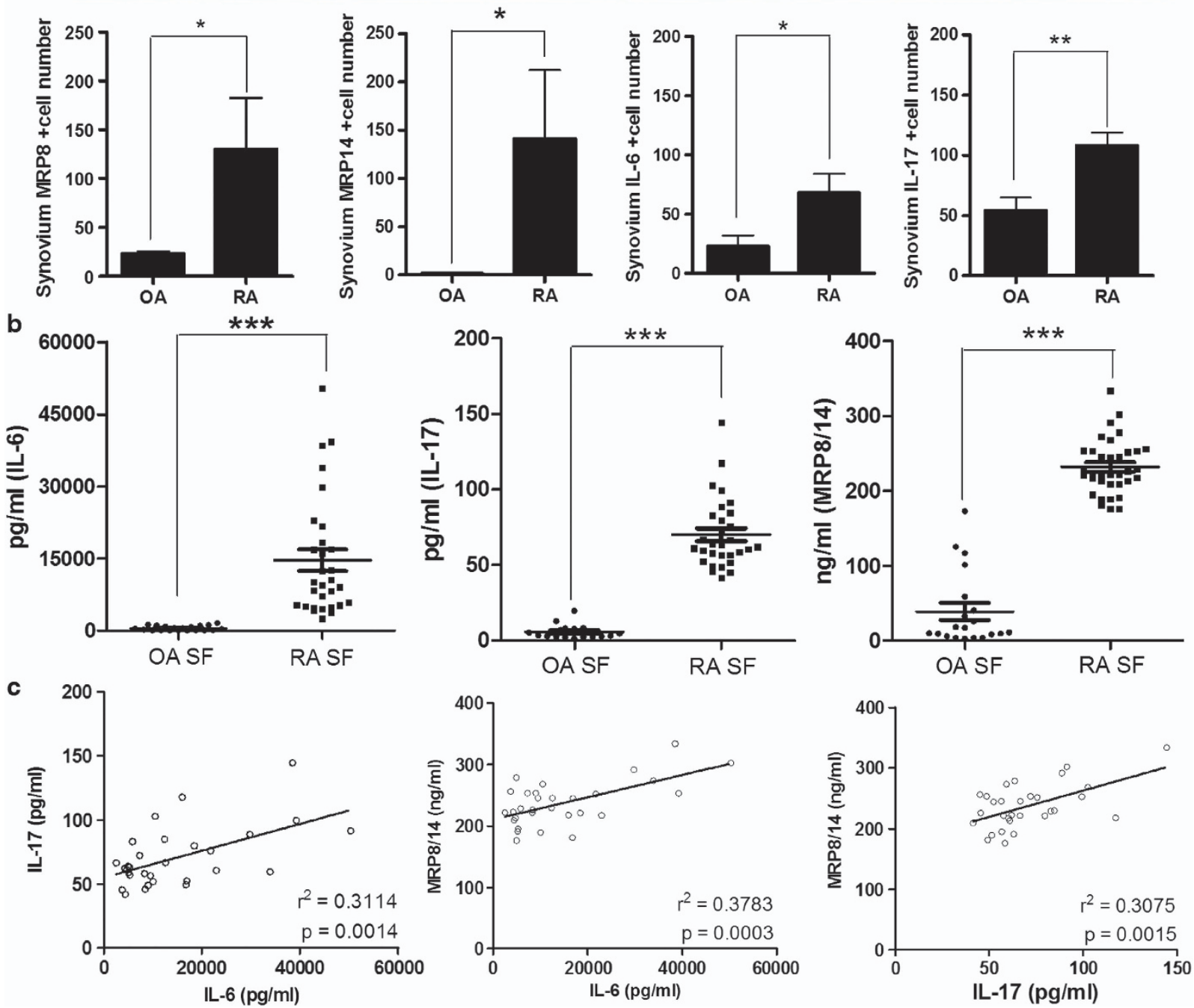

Figure 1 Elevated expression of MRP8, MRP14, IL-6 and IL-17 in RA ST and significant correlations among the levels of MRP8/MRP14, IL-6 and IL-17 in RA SF. (a) The expression of MRP8, MRP14, IL-6 and IL-17 were determined in the synovium of patients with RA $(n=3)$ or $\mathrm{OA}(n=3)$ by immunohistochemical staining. Representative photographs are shown. Data represent the average value calculated from three independent experiments. (b) Concentration of MRP8/MRP14, IL-6 and IL-17 in SF from patients with RA ( $n=30$ ) and OA $(n=20)$ were determined by ELISA. Each circle or square represents an individual patient; bars show mean \pm s.d. (c) Correlations between IL- 6 and IL-17, between MRP8/MRP14 and IL-6, and between MRP8/MRP14 and IL-17 concentrations were assessed in SF from RA patients. ${ }^{*} P<0.05,{ }^{*} P<0.01$ and $* * * P<0.001$. 
a

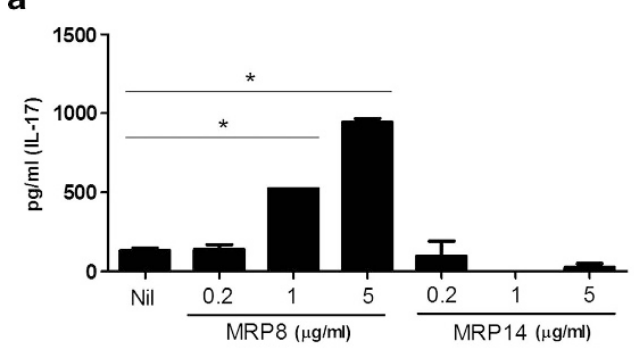

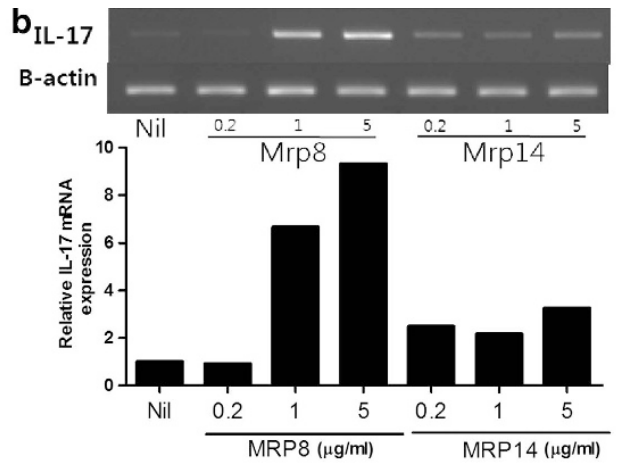
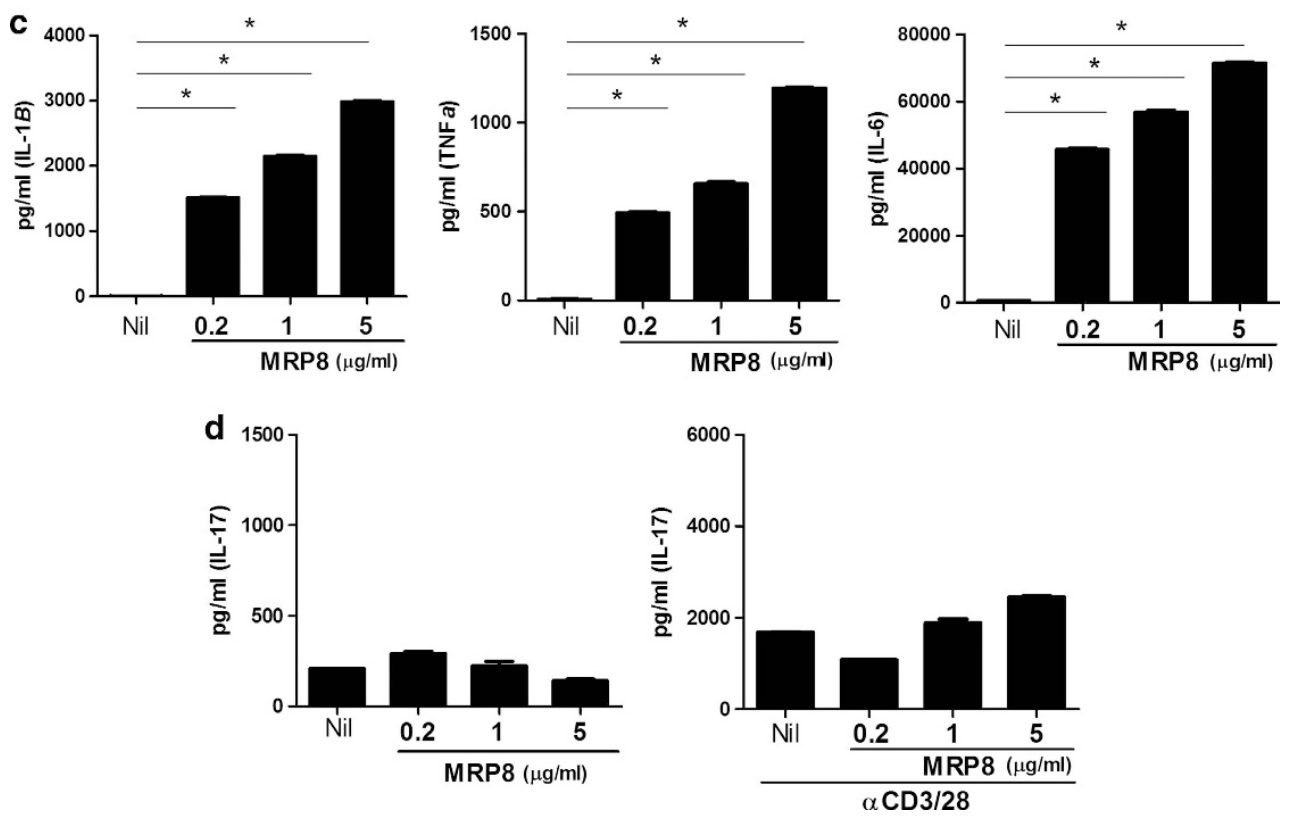

Figure 2 Induction of proinflammatory cytokines by MRP8 and MRP14 in PBMCs and CD4 + T cells. (a) Healthy PBMCs were cultured in the presence of MRP8 or MRP14 $\left(0,0.2,1\right.$ and $\left.5 \mu \mathrm{g} \mathrm{ml}^{-1}\right)$ for $72 \mathrm{~h}$, and the levels of IL-17 in the culture supernatants were determined by ELISA. (b) RNA was extracted and IL-17 mRNA expression was quantified using reverse-transcription PCR. mRNA levels were normalized to $\beta$-actin. (c) Healthy PBMCs were cultured in the presence of MRP8 or MRP14 $\left(0,0.2,1\right.$ and $\left.5 \mu \mathrm{g} \mathrm{ml} \mathrm{m}^{-1}\right)$ for $72 \mathrm{~h}$, and the levels of TNF $\alpha, I L-1 \beta$ and IL- 6 in the culture supernatants were determined by ELISA. (d) CD4 ${ }^{+}$T cells isolated from healthy PBMCs were cultured with MRP8 $\left(0,0.2,1\right.$ and $\left.5 \mu \mathrm{g} \mathrm{ml}^{-1}\right)$ and the levels of IL-17 in the culture supernatants were determined by ELISA. Data are representative of three independent experiments (mean and s.d.). ${ }^{*} P<0.001$.

predominant cell type in RA synovium, the pathogenic lesion of RA, and are also known to be a major source of IL-6 in addition to synovial macrophages. ${ }^{13}$ To investigate whether MRP8 further stimulates IL-6 production by FLS, we cultured FLS isolated from OA and RA patients in vitro in the presence of different concentrations of MRP8 $\left(0,1\right.$ and $\left.5 \mu \mathrm{g} \mathrm{ml}^{-1}\right)$ and analyzed the proinflammatory cytokine level, including TNF- $\alpha$, IL- $1 \beta$ and IL- 6 by ELISA. Concentration of IL- 6 in RA FLS was higher than that in OA FLS and significantly increased by MRP8 in a dose-dependent (Figure 3a) and time-dependent manner (Figure $3 \mathrm{~b}$ ). The result indicates that MRP8 greatly induces IL- 6 expression by RA FLS and may contribute to the high concentration of IL- 6 in RA SF. In contrast with IL-6, concentration of TNF- $\alpha$ and IL-1 $\beta$ in RA FLS culture supernatant was not significantly induced by MRP8 stimulation (data not shown), implying that FLS might not be a significant source of TNF- $\alpha$ and IL- $1 \beta$ in RA. ${ }^{27}$ To exclude any effect of lipopolysaccharide (LPS) contamination on the stimulatory activity of MRP8, we compared the levels of IL-6 expression among MRP8 $\left(5 \mu \mathrm{g} \mathrm{ml}^{-1}\right)$ - and LPS $\left(1 \mu \mathrm{g} \mathrm{ml}^{-1}\right)$-stimulated RA FLS. LPS induced much less IL-6 in RA FLS than MRP8 (data not shown), demonstrating that the induction of IL-6 by MRP8 stimulation in our study was not due to any LPS contamination but rather the effect of MRP8 itself.

Promotion of IL-6 production and Th17 differentiation by MRP8-stimulated RA FLS in vitro

Considering that IL-6 is a critical regulator for Th17 differentiation and its expression was elevated in MRP8-stimulated RA FLS, we hypothesized that this MRP8-stimulated production 

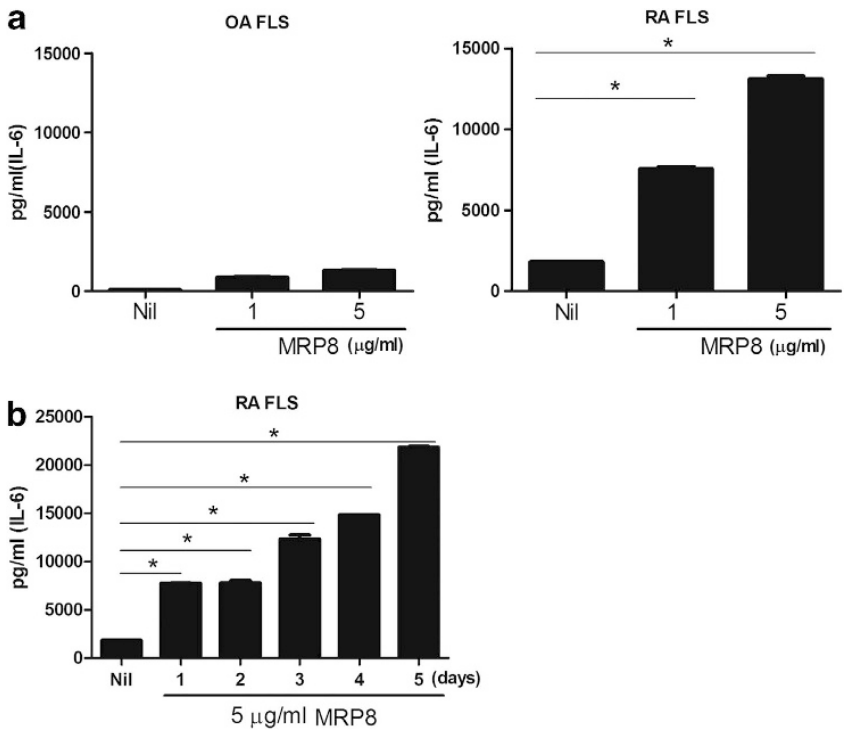

Figure 3 MRP8-induced upregulation of IL-6 production in RA FLS. (a) RA FLS and OA FLS were cultured with MRP8 (0, 1 and $5 \mu \mathrm{g} \mathrm{m}^{-1}$ ) for $72 \mathrm{~h}$, and the IL- 6 concentrations in the culture supernatants were measured by ELISA. (b) RA FLS were cultured with MRP8 $\left(5 \mu \mathrm{g} \mathrm{ml}^{-1}\right)$ for days indicated and the IL-6 concentrations in the culture supernatants were measured by ELISA. Data are representative of three independent experiments (mean and s.d.). ${ }^{*} P<0.001$.

of IL- 6 by FLS might in turn promote Th17 differentiation. To test this hypothesis, $\mathrm{CD} 44^{+} \mathrm{T}$ cells were purified, activated with anti-CD3/28 antibodies and cocultured with RA FLS, which were precultured in the presence or absence of MRP8 stimulation. The expression of IL-17, a signature cytokine of Th17 cells, was then analyzed by ELISA. A significant increase of IL-17 was observed in the coculture with MRP8-stimulated RA FLS compared with that in MRP8-untreated RA FLS (Figure 4a). Blocking of IL- 6 by IL-6-neutralizing monoclonal antibody subsequently reduced the stimulatory effect of MRP8-treated FLS on Th17 differentiation (Figure 4a) in the coculture of $\mathrm{CD}^{+} \mathrm{T}$ cells and FLS. These results suggested that when FLS was stimulated by MRP8, the level of IL- 6 was significantly enhanced, which subsequently facilitated Th17 differentiation in vitro. Notably, IL-6 level was remarkably increased in the coculture of MRP8-stimulated RA FLS and $\mathrm{CD}^{+}{ }^{+} \mathrm{T}$ cells compared with that in the monoculture of MRP8-stimulated RA FLS (Figure 4b). Moreover, coculturing of RA FLS and $\mathrm{CD}^{+} \mathrm{T}$ cells without MRP8-mediated activation of FLS also enhanced IL-6 production, indicating that cell-cell contact between RA FLS and $\mathrm{CD}^{+}{ }^{+} \mathrm{T}$ cells in the coculture might further amplify IL-6 production by RA FLS.

\section{TLR4-mediated signaling pathways involved in MRP8- \\ induced IL-6 expression in RA FLS}

TLR4 belongs to the family of pathogen-recognition receptors and has been demonstrated as the major receptor for MRPs in previous studies. ${ }^{28}$ The recognition of damage-associated molecular patterns or pathogen-associated molecular patterns,
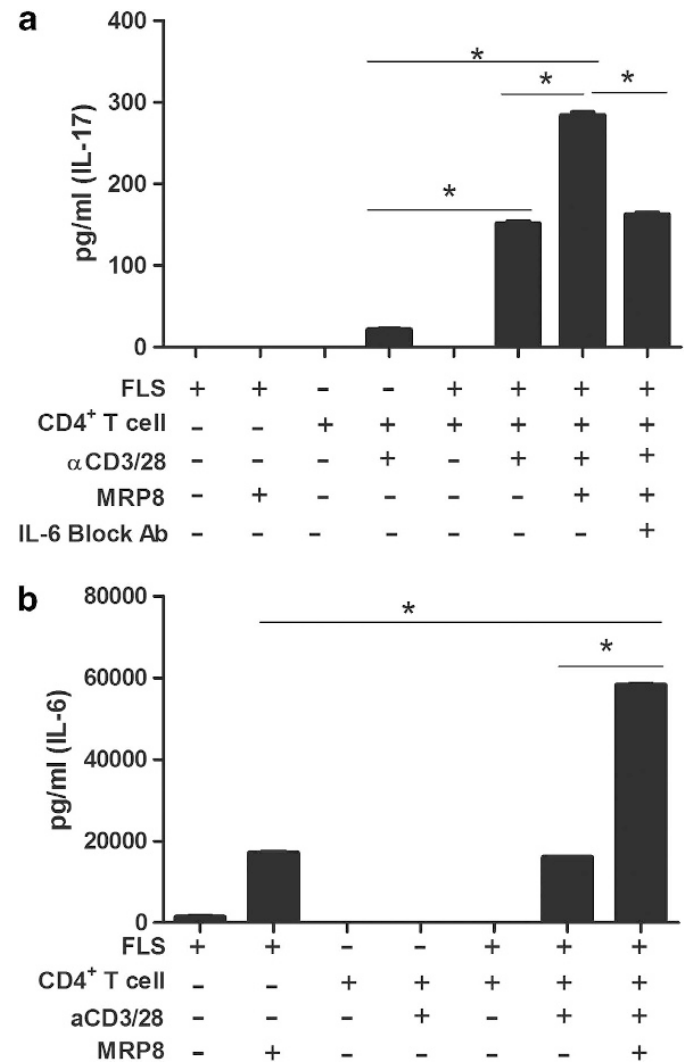

Figure 4 Promotion of IL- 6 production and Th17 differentiation by MRP8-stimulated RA FLS in vitro. (a, b) RA FLS and CD4 ${ }^{+} \mathrm{T}$ cells were cocultured at the 1:10 cell-to-cell ratio for $72 \mathrm{~h}$, in which RA FLS and CD4 ${ }^{+}$T cells were stimulated with MRP8 $\left(5 \mu \mathrm{g} \mathrm{ml}^{-1}\right)$ and anti-CD3/CD28 antibodies, respectively, before coculturing, when mentioned. For IL- 6 blockade (a), anti-IL-6 monoclonal antibody was added in the coculture. IL-17 (a) and IL-6 (b) levels in the culture supernatants were determined by ELISA. Data are representative of three independent experiments (mean and s.d.). ${ }^{*} P<0.001$.

such as MRPs and LPS, by TLR4 can stimulate intracellular signaling pathways through adaptor molecules such as MYD88 (myeloid differentiation primary response protein 88 ), resulting in activation of NF- $\kappa \mathrm{B}$, and subsequent induction of cytokines and cartilage-degrading proteinases. ${ }^{29}$ Therefore, we examined the effect of blocking TLR4 on the MRP8-stimulated increase of IL-6 in RA FLS, using anti-TLR4 antibody. As shown in Figure 5, treatment with anti-TLR4 antibody significantly reduced the stimulatory effect of MRP8 on the production of IL-6. To investigate further the downstream signaling pathway(s), we used known inhibitors of several signaling molecules, such as LY294002 (inhibitor of PI3K), SP600125 (inhibitor of c-Jun N-terminal kinase), PD98059 (inhibitor of extracellular signal-regulated kinase-1/2), SB203580 (inhibitor of p38 MAP kinase) and parthenolide (inhibitor of NF- $\kappa B$ ). Parthenolide is known to inhibit IкB kinase, thus preventing $\mathrm{I} \kappa \mathrm{B}$ degradation and NF- $\kappa \mathrm{B}$ activation. ${ }^{30} \mathrm{PI} 3 \mathrm{~K}$ is shown to activate protein kinase $\mathrm{C}$ and Ras family, which subsequently lead to the activation of NF- $\mathrm{KB}$ and MAP kinases, respectively. 


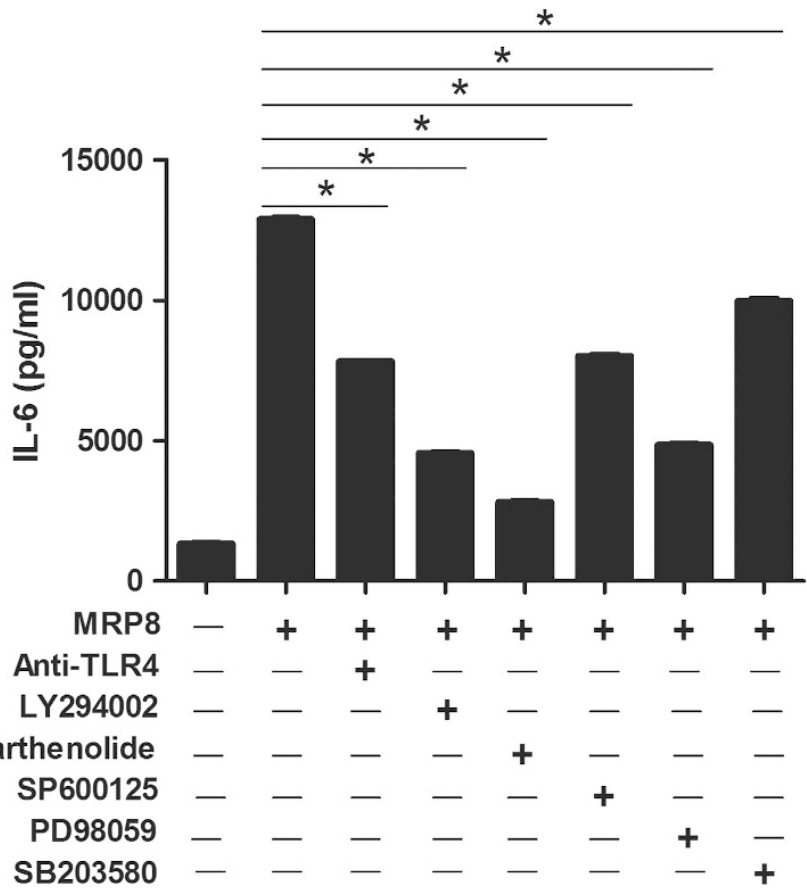

Figure 5 TLR4-mediated signaling pathways involved in MRP8induced IL-6 expression in RA FLS. IL- 6 production was assessed after RA FLS were cultured with $5 \mu \mathrm{g} \mathrm{ml}^{-1}$ MRP8 along with one of the signal inhibitors (anti-TLR4 antibody, LY294002, parthenolide, SP600125, PD98059 and SB203580). IL-6 levels in the culture supernatants were determined by ELISA. Data are representative of three independent experiments (mean and s.d.). $* P<0.001$.

MAP kinases, such as extracellular signal-regulated kinase, c-Jun N-terminal kinase and p38, when activated, trigger transcription factor activation for cytokine production. ${ }^{31}$ ELISA assay revealed that MRP8-stimulated IL-6 expression in FLS was significantly decreased in the presence of all the above inhibitor molecules (Figure 5). The results show that TLR4, PI3K, NF- $\mathrm{KB}$ and MAP kinases are involved in the MRP8-triggered signaling pathways, although some nonspecific effects by one or more inhibitors might also contribute to the inhibitory effects in some degree. The marked reduction of IL-6 by NF- $\kappa B$ inhibitor indicates that NF- $\kappa B$ has an essential role in MRP8-induced IL-6 expression by RA FLS. On the basis of these results, we suggest that MRP8 stimulated IL-6 production in FLS via the TLR4/PI3K/NF-KB and MAP kinase signaling pathways.

\section{DISCUSSION}

MRP8/MRP14 expression is strongly upregulated during various inflammatory and autoimmune disorders, such as psoriasis, juvenile idiopathic arthritis, inflammatory bowel disease and RA. ${ }^{20,32,33}$ In RA, plasma level of MRP8 and MRP14 is positively associated with clinical and laboratory markers of inflammation and radiographic damage. ${ }^{34}$ In fact, MRP8/MRP14 is the most enhanced protein in RA SF and its local release has been suggested. ${ }^{19}$ Serum level of MRP8/
MRP14 has been shown to be a reliable biomarker of diagnosis and prognosis for several rheumatic joint diseases, including RA. ${ }^{34}$ Activated macrophages and neutrophils infiltrating into inflamed synovium are the major sources for the increased levels of MRP8/MRP14 in RA ST and RA SF. ${ }^{35}$

In the present study, we verified that MRP8 and MRP14 are highly expressed in RA ST and RA SF compared with those in OA ST and OA SF, respectively. In line with the recent data, ${ }^{26}$ expression of IL-6 and IL-17, critical cytokines involved in pathogenesis of RA, was significantly elevated in RA ST and RA SF compared with that in OA ST and OA SF. We then investigated whether there was any correlation between MRP8 expression and IL-6 or IL-17 expression in SF of RA patients and found that there is indeed a significant correlation between them. To our knowledge, our data revealed for the first time that MRP8/MRP14 level correlates positively with IL-6 and IL-17 levels in RA SF.

Recently, Loser et al. ${ }^{14}$ demonstrated that MRP8 and MRP14 are the key factors linking inflammation and autoimmunity by showing that local MRP8 and MRP14 production is essential for the induction of autoreactive $\mathrm{CD} 8{ }^{+} \mathrm{T}$ cells and the development of systemic autoimmunity in a mouse autoimmune model. We examined the effect of MRP8 and MRP14 on PBMCs and $\mathrm{CD}^{+}{ }^{+} \mathrm{T}$ cells, and found that MRP8 dose dependently induces IL-17 expression in PBMCs. Our result that MRP14 did not induce IL-17 expression in PBMCs is complementing the finding that MRP14 is a regulatory unit preventing MRP8 from degradation and MRP8 is the active component of MRP8/MRP14 protein. ${ }^{22,36}$ However, MRP8 did not increase IL-17 expression in $\mathrm{CD} 4^{+} \mathrm{T}$ cells even upon stimulation with anti-CD3/CD28 antibodies. These data suggest that the induction of IL-17 in PBMCs by MRP8 might be due to an indirect effect through activation of phagocytes rather than direct activation of $\mathrm{CD}^{+}{ }^{+} \mathrm{T}$ cells in producing proinflammatory cytokines and, thus, providing a Th17-polarizing environment. MRP8 also enhanced the production of TNF- $\alpha$, IL-1 $\beta$ and IL-6 in PBMCs, indicating that the early increase of MRP8 level in synovium by infiltrated cells and its paracrine and autocrine positive feedback loop through TLR4 for the amplification of cytokine production could be a major contributor to the chronicity of RA. ${ }^{37}$

These findings prompted us to speculate that MRP8 might induce a local microenvironment, especially through upregulation of IL- 6 production by FLS, which could subsequently promote Th17 differentiation in RA synovium. IL-6 has been shown to be of particular importance in mouse Th17 differentiation. ${ }^{38}$ Furthermore, IL- 6 is known to be an inducer of human Th17 cell differentiation and the inhibition of IL-6 function by Tocilizumab, a humanized anti-IL-6-receptor antibody, was demonstrated to restore the Th17/regulatory T cell imbalance in RA patients. ${ }^{39,40}$ In RA, FLS have a key role in the local immune system by producing cytokines, chemokines and proteases that perpetuate inflammation and contribute to cartilage destruction. ${ }^{13}$ van Lent $e t$ al. ${ }^{21}$ reported that a single intra-articular injection of MRP8 induced TNF $\alpha$, IL-6, IL-1 $\beta$ and matrix metalloproteinases 
in synovium, resulting in joint inflammation and cartilage destruction in an experimental arthritis model. We found that MRP8 induced higher level of IL-6 by RA FLS than by OA FLS in a dose-dependent and time-dependent manner. However, TNF $\alpha$ and IL-1 $\beta$, the other pivotal proinflammatory cytokines involved in RA pathogenesis, were not induced by RA FLS on MRP8 stimulation. Our result suggests that RA FLS may be the major contributor of the marked increase of IL-6, but not a significant source of TNF $\alpha$ and IL-1 $\beta$ in RA synovium. ${ }^{27}$

Recently, van Hamberg et al. ${ }^{41}$ demonstrated that RA FLS, when cocultured with Th17 cells, induced a Th17-polarizing environment. They indicated that the possible factor for Th17 polarization would be the induced IL-6 in the RA FLS/Th17 cocultures. In addition, Lin et al. ${ }^{42}$ showed that the cysteinerich protein 61 (Cyr61), which is produced by FLS and is known to mediate cell adhesion and migration, promotes Th17 development in RA via upregulation of IL-6. Moreover, it was also reported that interaction of mesenchymal stem cells or FLS with PBMCs amplified IL-17A level and this amplification was associated with a significant increase of IL- $6{ }^{43}$ In the current study, we investigated whether MRP8 could further stimulate Th17 differentiation in a coculture system via upregulation of IL-6 by RA FLS, and found it was indeed the case. We also observed a remarkable increase of IL6 level in the coculture of MRP8-stimulated RA FLS and $\mathrm{CD}^{+} \mathrm{T}$ cells. The result is consistent with recent reports showing that coculturing FLS with PBMCs or Th17 cells further upregulate cytokine production, such as IL-6 and IL-8, by FLS through cell-cell contact. ${ }^{41,43}$ Adding IL-6-blocking antibody in RA FLS/CD4 ${ }^{+}$T-cell cocultures attenuated the stimulatory effect of MLR8 on Th17 differentiation. The results indicate that MRP8 can promote Th17 differentiation in RA synovium through enhancement of IL-6 production by RA FLS. Thus, MRP8 released by neutrophils, monocytes and activated macrophages in RA synovium could form a malicious feedback loop for stimulation of FLS and Th17, resulting in persistent inflammation in RA.

Although the receptor(s) responsible for MRP8 and MRP14 signaling is still under debate, it has lately been reported that TLR4 is the major receptor for MRP8 and MRP14 in monocytes and macrophages, and mRNA and protein levels of TLR4 are increased in RA FLS compared with those in OA FLS. ${ }^{18,44,45}$ Blockade of TLR4 inhibited the effect of MRP8 and MRP14 signaling on matrix metalloproteinases and IL-6 production in human chondrocytes. ${ }^{46}$ Furthermore, inhibition of TLR4 suppresses the severity of experimental arthritis by reducing cytokine production in arthritic joints. ${ }^{28}$ Interaction of MRP8 and/or MRP14 with RAGE (receptor of advanced glycation end product) has also been reported, although blocking of RAGE do not suppress stimulatory effect of MRP8 on osteoclasts. ${ }^{22}$ We analyzed the signal transduction pathway activated by ligation of MRP8 and TLR4 using specific inhibitors, and found that MRP8 stimulated IL-6 production by RA FLS via TLR4/PI3K/NF$\kappa \mathrm{B}$ and MAP kinase signaling pathways. The inhibitor studies indicate that NF- $\mathrm{KB}$ is critical in this MRP8-stimulated increase of IL-6 production. The finding that TLR4 inhibition did not completely suppress MRP8-induced IL-6 expression suggests that other receptors like RAGE may also be involved in ligation of MRP8 in FLS.

In conclusion, MRP8 has a crucial role in inducing Th17 cell differentiation through upregulation of IL- 6 expression by RA FLS, and thereby amplifies the effect of stimulatory interactions between RA FLS and Th17 cells. Targeting MRP8/MRP14 in vivo through gadolinium immunoparticles demonstrated enhancement of plaque with binding to inflammatory cells and reduction in inflammation in atherosclerosis. ${ }^{47}$ Neutralizing MRP8 in RA synovium in addition to currently available treatments may render a more effective therapeutic strategy for reducing inflammation and preventing cartilage and bone destruction in RA.

\section{CONFLICT OF INTEREST}

The authors declare no conflict of interest.

\section{ACKNOWLEDGEMENTS}

This work was supported by the Basic Science Research Program through the National Research Foundation of Korea (NRF), funded by the Ministry of Education, Science and Technology (grant number 2005-0048480) and by a grant of the Korea Health Technology R\&D Project, Ministry for Health, Welfare \& Family Affairs, Republic of Korea (grant number A092258).

1 Mclnnes IB, Schett G. The pathogenesis of rheumatoid arthritis. N Engl J Med 2011; 365: 2205-2219.

2 Boissier MC, Semerano L, Challal S, Saidenberg-Kermanac'h N, Falgarone G. Rheumatoid arthritis: from autoimmunity to synovitis and joint destruction. J Autoimmun 2012; 39: 222-228.

3 Koenders MI, Joosten LA, van den Berg WB. Potential new targets in arthritis therapy: interleukin (IL)-17 and its relation to tumour necrosis factor and IL-1 in experimental arthritis. Ann Rheum Dis 2006; 65 (Suppl 3), iii29-iii33.

4 Nakae S, Nambu A, Sudo K, Iwakura Y. Suppression of immune induction of collagen-induced arthritis in IL-17-deficient mice. J Immunol 2003; 171: 6173-6177.

5 Lubberts E, Koenders MI, Oppers-Walgreen B, van den Bersselaar L, Coenen-de Roo CJ, Joosten LA et al. Treatment with a neutralizing antimurine interleukin-17 antibody after the onset of collagen-induced arthritis reduces joint inflammation, cartilage destruction, and bone erosion. Arthritis Rheum 2004; 50: 650-659.

6 Hirota K, Hashimoto M, Yoshitomi H, Tanaka S, Nomura T, Yamaguchi T et al. T cell self-reactivity forms a cytokine milieu for spontaneous development of IL-17+ Th cells that cause autoimmune arthritis. J Exp Med 2007; 204: 41-47.

7 Egan PJ, van Nieuwenhuijze A, Campbell IK, Wicks IP. Promotion of the local differentiation of murine Th17 cells by synovial macrophages during acute inflammatory arthritis. Arthritis Rheum 2008; 58: 3720-3729.

8 Zhou L, Lopes JE, Chong MM, Ivanov II, Min R, Victora GD et al. TGF-betainduced Foxp3 inhibits $\mathrm{T}(\mathrm{H}) 17$ cell differentiation by antagonizing RORgammat function. Nature 2008; 453: 236-240.

9 Laurence A, O'Shea JJ. T(H)-17 differentiation: of mice and men. Nat Immunol 2007; 8: 903-905

10 Zhu J, Paul WE. Heterogeneity and plasticity of T helper cells. Cell Res 2010; 20: 4-12.

11 Dayer JM, Choy E. Therapeutic targets in rheumatoid arthritis: the interleukin-6 receptor. Rheumatology (Oxford) 2010; 49: 15-24.

12 Hashizume M, Mihara M. The roles of interleukin- 6 in the pathogenesis of rheumatoid arthritis. Arthritis 2011; 2011: 765624.

13 Bartok B, Firestein GS. Fibroblast-like synoviocytes: key effector cells in rheumatoid arthritis. Immunol Rev 2010; 233: 233-255. 
14 Loser K, Vogl T, Voskort M, Lueken A, Kupas V, Nacken W et al. The Tolllike receptor 4 ligands Mrp8 and Mrp14 are crucial in the development of autoreactive CD8 + T cells. Nat Med 2010; 16: 713-717.

15 Ehrchen JM, Sunderkötter C, Foell D, Vogl T, Roth J. The endogenous Tolllike receptor 4 agonist S100A8/S100A9 (calprotectin) as innate amplifier of infection, autoimmunity, and cancer. J Leukoc Biol 2009; 86: 557-566.

16 Foell D, Roth J. Proinflammatory S100 proteins in arthritis and autoimmune disease. Arthritis Rheum 2004; 50: 3762-3771.

17 Vogl T, Gharibyan AL, Morozova-Roche LA. Pro-inflammatory S100A8 and S100A9 proteins: self-assembly into multifunctional native and amyloid complexes. Int J Mol Sci 2012; 13: 2893-2917.

18 Vogl T, Tenbrock K, Ludwig S, Leukert N, Ehrhardt C, van Zoelen MA et al. Mrp8 and Mrp14 are endogenous activators of Toll-like receptor 4, promoting lethal, endotoxin-induced shock. Nat Med 2007; 13: 1042-1049.

19 Baillet A, Trocmé C, Berthier S, Arlotto M, Grange L, Chenau J et al. Synovial fluid proteomic fingerprint: S100A8, S100A9 and S100A12 proteins discriminate rheumatoid arthritis from other inflammatory joint diseases. Rheumatology (Oxford) 2010; 49: 671-682.

20 Hammer HB, Odegard S, Syversen SW, Landewe R, van der Heijde D, Uhlig T et al. Calprotectin (a major S100 leucocyte protein) predicts 10year radiographic progression in patients with rheumatoid arthritis. Ann Rheum Dis 2010; 69: 150-154.

21 van Lent PL, Grevers L, Blom AB, Sloetjes A, Mort JS, Vogl T et al. Myeloidrelated proteins S100A8/S100A9 regulate joint inflammation and cartilage destruction during antigen-induced arthritis. Ann Rheum Dis 2008; 67: 1750-1758.

22 Grevers LC, de Vries TJ, Vogl T, Abdollahi-Roodsaz S, Sloetjes AW, Leenen PJ et al. S100A8 enhances osteoclastic bone resorption in vitro through activation of Toll-like receptor 4: implications for bone destruction in murine antigen-induced arthritis. Arthritis Rheum 2011; 63: $1365-1375$.

23 van Lent PL, Blom AB, Schelbergen RF, Sloetjes A, Lafeber FP, Lems WF et al. Active involvement of alarmins S100A8 and S100A9 in the regulation of synovial activation and joint destruction during mouse and human osteoarthritis. Arthritis Rheum 2012; 64: 1466-1476.

24 Arnett FC, Edworthy SM, Bloch DA, McShane DJ, Fries JF, Cooper NS et al. The American Rheumatism Association 1987 revised criteria for the classification of rheumatoid arthritis. Arthritis Rheum 1988; 31: 315-324.

25 Kim KW, Cho ML, Kim HR, Ju JH, Park MK, Oh HJ et al. Up-regulation of stromal cell-derived factor 1 (CXCL12) production in rheumatoid synovial fibroblasts through interactions with T lymphocytes: role of interleukin-17 and CD4OL-CD40 interaction. Arthritis Rheum 2007; 56: 1076-1086.

$26 \mathrm{Ju} J \mathrm{JH}, \mathrm{Heo}$ YJ, Cho ML, Jhun JY, Park JS, Oh HJ et al. Modulation of STAT3 in rheumatoid Synovial T cells suppresses Th17 differentiation and increases the proportion of regulatory T cells. Arthritis Rheum 2012; 64: 3543-3552.

27 Feldmann M, Brennan FM, Maini RN. Role of cytokines in rheumatoid arthritis. Annu Rev Immunol 1996; 14: 397-440.

28 Goh FG, Midwood KS. Intrinsic danger: activation of Toll-like receptors in rheumatoid arthritis. Rheumatology (Oxford) 2012; 51: 7-23.

29 Sacre SM, Andreakos E, Kiriakidis S, Amjadi P, Lundberg A, Giddins G et al. The Toll-like receptor adaptor proteins MyD88 and Mal/TIRAP contribute to the inflammatory and destructive processes in a human model of rheumatoid arthritis. Am J Pathol 2007; 170: 518-525.

30 Saadane A, Masters S, DiDonato J, Li J, Berger M. Parthenolide inhibits IkappaB kinase, NF-kappaB activation, and inflammatory response in cystic fibrosis cells and mice. Am J Respir Cell Mol Biol 2007; 36: 728-736.

31 Jeffrey KL, Camps M, Rommel C, Mackay CR. Targeting dual-specificity phosphatases: manipulating MAP kinase signalling and immune responses. Nat Rev Drug Discov 2007; 6: 391-403.

32 Wittkowski H, Kuemmerle-Deschner JB, Austermann J, Holzinger D, Goldbach-Mansky R, Gramlich K et al. MRP8 and MRP14, phagocytespecific danger signals, are sensitive biomarkers of disease activity in cryopyrin-associated periodic syndromes. Ann Rheum Dis 2011; 70: 2075-2081.
33 Holzinger D, Frosch M, Kastrup A, Prince FH, Otten MH, Van SuijlekomSmit LW et al. The Toll-like receptor 4 agonist MRP8/14 protein complex is a sensitive indicator for disease activity and predicts relapses in systemiconset juvenile idiopathic arthritis. Ann Rheum Dis 2012; 71: 974-980.

34 Hammer HB, Odegard S, Fagerhol MK, Landewé R, van der Heijde D, Uhlig $\mathrm{T}$ et al. Calprotectin (a major leucocyte protein) is strongly and independently correlated with joint inflammation and damage in rheumatoid arthritis. Ann Rheum Dis 2007; 66: 1093-1097.

35 Youssef $\mathrm{P}$, Roth J, Frosch M, Costello P, Fitzgerald O, Sorg C et al. Expression of myeloid related proteins (MRP) 8 and 14 and the MRP8/14 heterodimer in rheumatoid arthritis synovial membrane. J Rheumatol 1999; 26: 2523-2528

36 Manitz MP, Horst B, Seeliger S, Strey A, Skryabin BV, Gunzer M et al. Loss of S100A9 (MRP14) results in reduced interleukin-8-induced CD11b surface expression, a polarized microfilament system, and diminished responsiveness to chemoattractants in vitro. Mol Cell Biol 2003; 23: 1034-1043.

37 Sunahori K, Yamamura M, Yamana J, Takasugi K, Kawashima M, Yamamoto $\mathrm{H}$ et al. The S100A8/A9 heterodimer amplifies proinflammatory cytokine production by macrophages via activation of nuclear factor kappa $\mathrm{B}$ and p38 mitogen-activated protein kinase in rheumatoid arthritis. Arthritis Res Ther 2006; 8: R69.

38 Bettelli E, Carrier Y, Gao W, Korn T, Strom TB, Oukka M et al. Reciprocal developmental pathways for the generation of pathogenic effector TH17 and regulatory T cells. Nature 2006; 441: 235-238.

39 Acosta-Rodriguez EV, Napolitani G, Lanzavecchia A, Sallusto F. Interleukins 1 beta and 6 but not transforming growth factor-beta are essential for the differentiation of interleukin 17-producing human T helper cells. Nat Immunol 2007; 8: 942-949.

40 Samson M, Audia S, Janikashvili N, Ciudad M, Trad M, Fraszczak J et al. Brief Report: Inhibition of interleukin- 6 function corrects Th17/Treg cell imbalance in patients with rheumatoid arthritis. Arthritis Rheum 2012; 64: 2499-2503.

41 van Hamburg JP, Asmawidjaja PS, Davelaar N, Mus AM, Colin EM, Hazes JM et al. Th17 cells, but not Th1 cells, from patients with early rheumatoid arthritis are potent inducers of matrix metalloproteinases and proinflammatory cytokines upon synovial fibroblast interaction, including autocrine interleukin-17A production. Arthritis Rheum 2011; 63: 73-83.

42 Lin J, Zhou Z, Huo R, Xiao L, Ouyang G, Wang L et al. Cyr61 induces IL-6 production by fibroblast-like synoviocytes promoting Th17 differentiation in rheumatoid arthritis. J Immunol 2012; 188: 5776-5784.

43 Eljaafari A, Tartelin ML, Aissaoui H, Chevrel G, Osta B, Lavocat F et al. Bone marrow-derived and synovium-derived mesenchymal cells promote Th17 cell expansion and activation through caspase 1 activation: contribution to the chronicity of rheumatoid arthritis. Arthritis Rheum 2012; 64: 2147-2157.

44 Ospelt C, Brentano F, Rengel Y, Stanczyk J, Kolling C, Tak PP et al. Overexpression of toll-like receptors 3 and 4 in synovial tissue from patients with early rheumatoid arthritis: toll-like receptor expression in early and longstanding arthritis. Arthritis Rheum 2008; 58: 3684-3692.

45 Tamaki Y, Takakubo Y, Hirayama T, Konttinen YT, Goodman SB, Yamakawa $\mathrm{M}$ et al. Expression of Toll-like receptors and their signaling pathways in rheumatoid synovitis. J Rheumatol 2011; 38: 810-820.

46 Bobacz K, Sunk IG, Hofstaetter JG, Amoyo L, Toma CD, Akira S et al. Tolllike receptors and chondrocytes: the lipopolysaccharide-induced decrease in cartilage matrix synthesis is dependent on the presence of toll-like receptor 4 and antagonized by bone morphogenetic protein 7. Arthritis Rheum 2007; 56: 1880-1893.

47 Maiseyeu A, Badgeley MA, Kampfrath T, Mihai G, Deiuliis JA, Liu C et al. In vivo targeting of inflammation-associated myeloid-related protein 8/14 via gadolinium immunonanoparticles. Arterioscler Thromb Vasc Biol 2012; 32: 962-970.

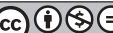

This work is licensed under a Creative Commons Attribution-NonCommercial-NoDerivs 3.0 Unported License. To view a copy of this license, visit http:// creativecommons.org/licenses/by-nc-nd/3.0/ 